\title{
Periostin as a Biomarker of Allergic Inflammation in Atopic Bronchial Asthma and Allergic Rhinititis (a Pilot Study)
}

\author{
DOI: $10.17691 / \mathrm{stm} 2020.12 .5 .04$
}

Received June 11, 2020

S.V. Krasilnikova, MD, PhD, Assistant, Department of Ear, Nose, and Throat";

E.V. Tush, MD, PhD, Associate Professor, Department of Hospital Pediatrics ${ }^{1}$;

P.A. Frolov, Assistant, Department of Pediatrics;

D.Yu. Ovsyannikov, MD, DSc, Head of the Department of Pediatrics;

A.B. Terentyeva, MD, PhD, Associate Professor, Department of Ear, Nose, and Throat ${ }^{1}$;

N.I. Kubysheva, DSc, Senior Researcher, Research Laboratory "Clinical Linguistics"3;

T.I. Eliseeva, MD, PhD, Associate Professor, Professor, Department of Hospital Pediatrics ${ }^{1}$

${ }^{1}$ Privolzhsky Research Medical University, 10/1 Minin and Pozharsky Square, Nizhny Novgorod, 603005, Russia; 2Peoples' Friendship University of Russia (RUDN University), 6 Miklukho-Maklaya St., Moscow, 117198, Russia;

${ }^{3}$ Kazan Federal University, 18 Kremlyovskaya St., Kazan, Republic of Tatarstan, 420008, Russia

The involvement of periostin in Th2-dependent allergic inflammation has been documented. However, the significance of periostin as a biomarker of local allergic inflammation in the nasal mucosa (NM) of patients with atopic bronchial asthma (BA) and allergic rhinitis (AR) is yet to be determined.

The aim of the study was to determine the presence of periostin and evaluate its role as a non-invasive marker of allergic inflammation in the nasal secretions of children with atopic BA and AR.

Materials and Methods. In 43 patients aged 4-17 years with atopic BA and AR, the NM was examined using nasal video-endoscopy and (if indicated) computed tomography; the amount of periostin in the nasal secretion was determined by the enzyme immunoassay.

Results. Exacerbation of AR was accompanied by a statistically significant increase in the level of periostin in the nasal secretion: up to $0.84[0.06 ; 48.79] \mathrm{ng} / \mathrm{mg}$, whereas in remission, that was $0.13[0.00 ; 0.36] \mathrm{ng} / \mathrm{mg} ; \mathrm{p}=0.04$. This value increased progressively as the severity of $A R$ increased from $0.16[0.00 ; 0.36] \mathrm{ng} / \mathrm{mg}$ in the mild course to $0.20[0.00 ; 9.03] \mathrm{ng} / \mathrm{mg}$ in AR of moderate severity, and to $10.70[0.56 ; 769.20] \mathrm{ng} / \mathrm{mg}$ in most severe cases; $\mathrm{p}=0.048$. Hypertrophy or polyposis of the nasal and/or paranasal mucosa was detected in $34.9 \%(15 / 43)$ of the examined patients. The concentration of periostin in the nasal secretion was lower in children without NM hypertrophy: $0.18[0.001 ; 4.30] \mathrm{ng} / \mathrm{mg}$ vs $0.78[0.13 ; 162.10] \mathrm{ng} / \mathrm{mg}$ in patients with NM hypertrophy; the differences were close to statistically significant: $p=0.051$. The level of nasal periostin depended on the clinical form of hypertrophy in the sinonasal mucosa, reaching $0.17[0.00 ; 0.32] \mathrm{ng} / \mathrm{mg}$ in children with polyposis hyperplasia of NM and $21.6[10.70 ; 1516.80] \mathrm{ng} / \mathrm{mg}$ - with hypertrophy of the NM in the medial surface of the concha; $p=0.02$.

Conclusion. Exacerbation and increased severity of AR in patients with atopic BA are accompanied by an increased level of periostin in the nasal secretion. This allows us to consider the level of nasal periostin as a biomarker of local allergic inflammation in the NM of patients with atopic BA combined with AR. Hypertrophic changes in the sinonasal mucosa are generally accompanied by an increased level of nasal periostin; specifically, this level significantly depends on the clinical form of mucous membrane hypertrophy and requires additional studies.

Key words: periostin; bronchial asthma; allergic rhinitis; chronic rhinosinusitis with polyps.

How to cite: Krasilnikova S.V., Tush E.V., Frolov P.A., Ovsyannikov D.Yu., Terentyeva A.B., Kubysheva N.I., Eliseeva T.I. Periostin as a biomarker of allergic inflammation in atopic bronchial asthma and allergic rhinitis (a pilot study). Sovremennye tehnologii v medicine 2020; 12(5): 37, https://doi.org/10.17691/stm2020.12.5.04

\section{Introduction}

Diseases of the upper respiratory tract (URT), including allergic rhinitis (AR) and allergic rhinosinusitis, are the most common comorbidities in patients with atopic bronchial asthma (BA) and can have a negative effect on its course. In this regard, current consensus documents recommend assessing the URT status at all stages of BA management [1-4].
The common pathogenetic mechanism of BA and allergic rhinitis/rhinosinusitis is allergic inflammation $[1,5,6]$. This may be associated with pathological remodeling of the respiratory tract, including the mucous membrane of the nose and paranasal sinuses [7]. Manifestations of URT remodeling in AR and allergic rhinosinusitis include epithelial hyperplasia, increased deposition and degradation of extracellular matrix components, and accumulation of plasma proteins [8].

Corresponding author: Tatyana I. Eliseeva, e-mail: eliseevati@yandex.ru 
The resulting hypertrophic changes in the sinonasal mucosa and the formation of polyps in the sinonasal zone aggravate the nasal obstruction, seriously impairing the quality of life of patients and having a negative impact on the achievement of asthma control [9-11].

Some authors point that hypertrophic and hyperplastic changes in the sinonasal mucosa are observed mainly in people over the age of 40 [12]. However, our studies and reports by others indicate that the debut of hypertrophy and hyperplasia can also occur in childhood, although there is no verified data on the prevalence of this pathology in children $[3,13,14]$. According to Karpova et al. [14], in children, polyposis-associated changes in the mucosa of the nose and paranasal sinuses are mainly due to AR.

In patients with allergic airway inflammation, no clear mechanism and risk factors for pathological remodeling of URT in hypertrophy and hyperplasia have been established until now [12]. The proposed hypotheses implicate the endotype and severity of allergic inflammation, which, in turn, are characterized by respective biomarkers [12, 15-17].

At present, at least two subtypes of inflammation have been described in BA and comorbid disorders of the URT: with a high activity of T-helper lymphocytes of the second type (Th2) and with a low activity of Th2 cells [12]. The subtype with a high Th2 response is the most common in BA patients, especially in children. It is associated with atopic syndrome and is characterized by a good response to therapy with topical glucocorticoids $[12,18,19]$. Th2-dependent allergic inflammation can trigger remodeling of the NM and contribute to hypertrophic and hyperplastic changes, including polyposis [20-23]. Patients with a Th2-dependent inflammatory endotype have the most severe and refractory course of the disease [24, 25].

Numerous cytokines are involved in inflammation of the Th2-dependent endotype. Among them are the so-called alarmins, initiators of Th2-inflammation: IL33, IL-25, and thymic stromal lymphopoietin [26-29]. It is assumed that alarmins promote the expression of IL-4, IL-5, and IL-13, an increase in IgE antibody titers, eosinophilia, and increased levels of periostin. These cytokines are involved in the mechanism of the Th2dependent inflammatory response, as well as in the associated pathological remodeling of the airways [12, 30]. It is, therefore, important to know biomarkers of allergic inflammation and pathological remodeling of the mucous membrane of the nose and paranasal sinuses in patients with BA, including children. Currently, periostin is recognized as a biomarker of advanced allergic inflammation of the second type [31].

Periostin is a matricellular protein with a molecular mass of $90 \mathrm{kDa}$; it is produced in response to inflammatory stimuli mediated by IL-4, IL-5, and IL-3 by many cells, including epithelial cells and fibroblasts $[7,32]$. There is evidence that periostin modulates URT inflammation and remodeling, but its precise functions are not fully understood [33]. Periostin is able to induce the differentiation of fibroblasts into myofibroblasts and enhance fibrosis by binding to other proteins of the extracellular matrix, such as type I collagen, fibronectin, and tenascin $\mathrm{C}$, as well as by inducing collagen fibrillogenesis and cross-linking [34]. Periostin can influence epithelial remodeling, promoting epithelial-mesenchymal transition [34], in which cells of the respiratory epithelium gradually transform into mesenchymal cells in the process of developing fibrosis [35]. Basal secretion of periostin by epithelial cells can change the underlying matrix by modifying the deposition and crosslinking of collagen fibrils [34].

Thus, considering the available data, periostin can be called a recognized biomarker of allergic inflammation of the second type and a potential marker of the associated pathological remodeling. It should be noted that most of the data on the role of periostin in inflammation of the second type and pathological remodeling in patients with chronic allergic airway diseases were obtained by invasive techniques, i.e., by studying tissue biopsies and/or determination of periostin in blood serum [33-35].

Until now, the non-invasive quantification of periostin in bio-substrates (for example, in nasal secretions) remained insufficiently developed. There are only isolated reports on the measurement of periostin in nasal secretions of patients with atopic asthma and nasal symptoms. We found a study by Pham et al. [36], which demonstrated abnormally high levels of nasal periostin in patients with asthma that increased even more with asthma exacerbation. In those cases when BA and AR were combined, the levels of nasal periostin were significantly higher than in patients with asthma alone (520.19 and $4.71 \mathrm{pg} / \mathrm{ml}$, respectively; $p<0.05$ ). However, this work did not analyze relations between the severity of nasal symptoms and the amount of nasal periostin and did not consider the role of hypertrophic changes in the sinonasal mucosa.

Studying the presence of periostin in the nasal secretion of patients with atopic asthma and nasal symptoms is essential to determine the value of periostin as a non-invasive marker of type 2 allergic inflammation and the associated pathological remodeling of the airways.

The aim of the study was to measure the level of periostin and evaluate its role as a marker of allergic inflammation in the nasal secretions of children with atopic bronchial asthma combined with allergic rhinitis, considering the clinical manifestations and hypertrophic changes in the mucosa of the nose and/or paranasal sinuses.

\section{Materials and Methods}

This pilot non-randomized single-center observational study was conducted in accordance with the requirements of the Helsinki Declaration (2013). The protocol was approved by the Ethics Committee of the 
Privolzhsky Research Medical University. Informed consent was obtained from patients aged 15 to 17 years and from the parents of children under 15 years old in accordance with Federal Law No.323 of November 21, 2011 "On the basics of protecting the health of citizens in the Russian Federation".

The study included 43 children aged 4 to 17 years (average age - 9.0 [7.0; 13.0] years); among them, boys - 67\% (29/43), girls - 33\% (14/43). The children underwent treatment for atopic BA and AR in the Children's City Clinical Hospital No.1 of Nizhny Novgorod in 2019-2020. The study inclusion criterion was the diagnosis of asthma made in accordance with the current international and national recommendations [1]. The exclusion criteria were acute infectious diseases, fever, diabetes mellitus, autoimmune disorders, primary immuno-deficiencies, oncological diseases, and oral administration of glucocorticoids [37]. The diagnosis and severity of asthma were determined by the attending physician according to the GINA recommendations available at that time [1]. Treatment of BA and AR was carried out by the accepted methodology $[1,38]$.

All children underwent general clinical examination and assessment of susceptibility to antigens by detecting IgE antibodies or by skin tests to common allergens known to cause allergies in populations of the Volga-Vyatka region of Russia [39]. Routine examination of the ENT organs, rhino video endoscopy using flexible optics with $3.2 \mathrm{~mm}$ outer diameter (Atmos, Germany), as well as CT of the paranasal sinuses (when indicated) were performed [5]. The Total Nasal Symptom Score (TNSS) scale was used to assess the severity of the nasal symptoms [40]. The Asthma Control Questionnaire-5 (ACQ-5) was used to quantify the level of BA control [41].

Collection of nasal secretion specimens for subsequent determination of periostin was carried out using Merocel spongy swabs (Medtronic, USA). Preweighed swabs were placed under the mid-concha on each side of the nose for $2 \mathrm{~min}$. Then, the swabs with the absorbed nasal secretion were re-weighed and mixed with $1.5 \mathrm{ml}$ of saline in a tube [42]. The tube was placed in a shaker for $10 \mathrm{~min}$, then centrifuged at $1500 \mathrm{rpm}$ for $10 \mathrm{~min}$. The collected supernatant was stored at $-20^{\circ} \mathrm{C}$ for no longer than two weeks. Periostin in the nasal secretion was quantified using the Human Periostin/ OSF-2 ELISA Kit (Aviscera Bioscience, Inc., USA) and an ALISEI Quality system automatic immunoassay analyzer (Radim, Italy) [43]. In accordance with the manufacturer's instructions, the measurement was performed twice for each patient (paired wells). For the subsequent analysis, the mean of the two values was used. The periostin content was expressed in nanograms per $1 \mathrm{mg}$ of nasal secretion.

Statistical processing of the data. The study was pilot in nature; therefore, no minimal sample size required for statistical significance was calculated. The statistical analysis was performed using Statgraphics Centurion package, v. 16.1.17. To determine the normality of data distribution for quantitative comparison, standardized skewness and standardized kurtosis were calculated. If the calculated values of these indicators were outside the range $-2 \ldots+2$, then the original data sets were considered different from normal. For the principal analyzed parameter - concentration of periostin in the nasal secretion - the standardized asymmetry and standardized kurtosis exceeded a value of +5 . Thus, we considered the periostin data distribution as different from the normal one; accordingly, we applied nonparametric tests to determine the differences between the groups. For two compared groups, this was the Wilcoxon W-test (Mann-Whitney) - a comparison of the medians of the two data samples; here, the data are presented as Me [Q1; Q3], where Me is the median value and [Q1; Q3] are the first and third quartiles. The Kruskal-Wallis test (KW test) was used to compare the medians between several groups. The relationship between the parameters was assessed using Spearman's rank correlation (p). Differences between qualitative characteristics were analyzed using the $\chi^{2}$ criterion. The differences were considered statistically significant at $p<0.05$.

\section{Results}

Clinical characteristics of the patients. The median age of the examined children was 9.0 [7.0; 13.0] years, boys and girls were comparable in age. All the examined patients with atopic BA showed signs of AR. In $14 \%$ (6/43) of children, the AR course was mild, in $67.4 \%(29 / 43)$ - moderate, and in $18.6 \%(8 / 43)-$ severe. In the majority $(81.4 \%, 35 / 43)$ of patients, AR was characterized by a persistent course, whereas an intermittent course was noted in $18.6 \%$ (8/43) of children. $A R$ in remission was diagnosed in $30.2 \%(13 / 43)$ of patients and exacerbated AR - in 69.8\% (30/43).

Most of the patients had comorbid URT disorders. Thus, according to the results of video endoscopic examination, $34.9 \% \quad(15 / 43)$ of children showed hypertrophy of the nasal mucous membrane of varying severity: from local hypertrophy of the mucous membrane of the medial surface of the concha $(n=9)$ to polyposis extending to the paranasal sinuses $(n=6)$. Children with hypertrophic changes were slightly older than those without them $(W=281.0 ; p=0.07)$, no significant gender differences were found $(W=211.5$; $p=0.6)$. The course of $A R$ in children with NM hypertrophic changes was moderate to severe in $46.7 \%$ (7/15) of cases, severe in $53.3 \%$ (8/15). Among patients with mild AR, no hypertrophic changes in the sinonasal mucosa were detected. Thus, hypertrophic changes in the NM were significantly more frequent in patients with moderate and severe AR $\left(\chi^{2}=19.6 ; p=0.001\right)$. Hypertrophy of the pharyngeal tonsil was noted in $72 \%$ (31/43) of children; anomalies of intranasal structures, mainly, the curvature of the nasal septum, were found in $72 \%(31 / 43)$ of children. 
Table 1

Periostin content in nasal secretions of children with atopic bronchial asthma and allergic rhinitis (Me [Q1; Q3])

\begin{tabular}{lcccc}
\hline \multicolumn{1}{c}{ Indicators } & All patients $(n=43)$ & \multicolumn{2}{c}{ Period of allergic rhinitis } & Statistical differences \\
& & Remission $(n=13)$ & Exacerbation $(n=30)$ & between groups \\
\hline TNSS (points) & $5.0[3.0 ; 7.0]$ & $3.0[2.0 ; 5.0]$ & $6.0[4.5 ; 8.5]$ & $W=360.5 ; p=0.0001$ \\
\hline Periostin $(\mathrm{ng} / \mathrm{mg})$ & $0.28[0.01 ; 10.69]$ & $0.13[0.00 ; 0.36]$ & $0.84[0.06 ; 48.79]$ & $W=274.0 ; p=0.04$ \\
\hline
\end{tabular}

The severity of nasal symptoms in children with BA and AR according to the TNSS averaged at 5.0 [3.0; 8.0] points. These values were changing in the course of AR: from 3.0 [2.0; 5.0] points in remission to 6.0 [4.0; 8.0] points in the period of $A R$ exacerbation ( $W=316.0$; $p=0.001$ ) (Table 1). The rhinoscopic picture of $A R$ in children with BA was characterized by a changed color of the NM, the presence or absence of edema, and discharge in the nasal passages. There was a trend to lower TNSS values in patients with physiological color of NM: $2.5[0.0 ; 5.0]$ points; in patients with pale NM in the nasal concha, the score was $5.0[3.0 ; 7.0]$, and in patients with hyperemia $-7.0[6.0 ; 9.5](\mathrm{KW}=5.1$; $\mathrm{p}=0.08$ ).

Periostin in nasal secretions of patients with different clinical courses of allergic rhinitis. The median concentration of periostin in nasal secretions of children with atopic BA and AR was 0.28 [0.01; 10.69] $\mathrm{ng} / \mathrm{mg}$ (see Table 1). No correlation of this parameter with age $(R=0.04 ; p=0.78)$ or gender $(W=174.0 ; p=0.46)$ of patients was found.

The concentration of periostin in the nasal secretion correlated with the period of AR: it was significantly higher in patients with AR exacerbation: 0.84 [0.06; 48.79] $\mathrm{ng} / \mathrm{mg}$, whereas in remission, it was 0.13 [0.00; $0.36] \mathrm{ng} / \mathrm{mg}(\mathrm{W}=274.0 ; p=0.04)$. In addition, the levels of periostin significantly correlated with the severity of AR: the levels as low as $0.16[0.00 ; 0.36] \mathrm{ng} / \mathrm{mg}$ were found in children with mild $A R(n=6)$ and the maximal values $10.70[0.56 ; 769.20] \mathrm{ng} / \mathrm{mg}$ were found in children with a severe course of the disease $(n=8)$. In AR of moderate severity $(n=29)$, the concentration of periostin was 0.20 $[0.00 ; 9.03] \mathrm{ng} / \mathrm{mg}(\mathrm{KW}=6.1 ; \mathrm{p}=0.048)$.

An additional correlation was found between the level of periostin in the nasal secretion and the total severity of nasal symptoms, assessed by the TNSS scale: $R=0.31$ at $p=0.04$ (Table 2). Thus, an aggravation of the $A R$ symptoms was accompanied by a progressive increase in the content of periostin in the nasal secretion.

We also analyzed the relationship between the presence of periostin in the nasal secretion and the severity of individual AR symptoms (see Table 2). A direct correlation was detected between the level of periostin in the nasal secretion and the severity of rhinorrhea: $R=0.36 ; p=0.02$. The severity of itching, sneezing, or nasal obstruction had no significant correlation with the nasal periostin under the given conditions.
Table 2

Correlations between the severity of symptoms of allergic rhinitis (TNSS scale, points) and the level of periostin in nasal secretions

\begin{tabular}{lcc}
\hline \multicolumn{1}{c}{ Clinical parameter } & $\mathbf{R}$ & $\mathbf{p}$ \\
\hline Rhinorrhea & $\mathbf{0 . 3 6}$ & $\mathbf{0 . 0 2}$ \\
Itching & 0.16 & 0.32 \\
Sneezing & 0.13 & 0.39 \\
Obstruction & 0.21 & 0.19 \\
\hline TNSS & $\mathbf{0 . 3 1}$ & $\mathbf{0 . 0 4}$ \\
\hline
\end{tabular}

Periostin in nasal secretions of patients with hypertrophy of the sinonasal mucosa. Our study showed that patients with hypertrophic changes in the sinonasal mucosa $(n=15)$ had higher levels of periostin in the nasal secretion: $0.78[0.13 ; 162.10] \mathrm{ng} / \mathrm{mg}$ compared with children without NM hypertrophy $(n=28)$ : 0.18 [0.001; 4.30] ng/mg; the differences were close to significant: $W=286.5 ; p=0.051$.

We then analyzed changes in the periostin levels in various clinical forms of NM hypertrophy. In 9 patients with $B A$ and $A R$, there was hypertrophy of the mucous membrane in the medial surface of the concha; in 6 patients, there was polyposis of the NM, extending to the paranasal sinuses. The level of periostin in the nasal secretion of children with hypertrophies $(n=9)$ was 21.6 [10.7; 1516.8] ng/mg, which was significantly higher than that in children with polyposis $(n=6): 0.17$ [0.001; 0.32] $\mathrm{ng} / \mathrm{mg} ; \mathrm{W}=48.0 ; \mathrm{p}=0.02$ (Figures 1, 2).

In figures, fragments of nasal video-endoscopy in patients with $B A$ and $A R$ who had various hyperplastic and hypertrophic changes in the sinonasal mucosa are shown. Notably, in a female patient with atopic BA and AR who had NM hypertrophy in the medial surface of the posterior ends of the inferior conchae, the level of periostin in the nasal secretion was high: $10.7 \mathrm{ng} / \mathrm{mg}$ (see Figure 1). Along with that, in another female patient with atopic BA and AR who had polyposis-associated hypertrophy of the NM (with obstruction of the middle nasal passage on the left), the level of nasal periostin was significantly lower: $0.056 \mathrm{ng} / \mathrm{mg}$ (see Figure 2).

We found no significant correlation between the level of periostin and changes in the nasal architectonics or the state of the pharyngeal tonsil. Thus, the median 


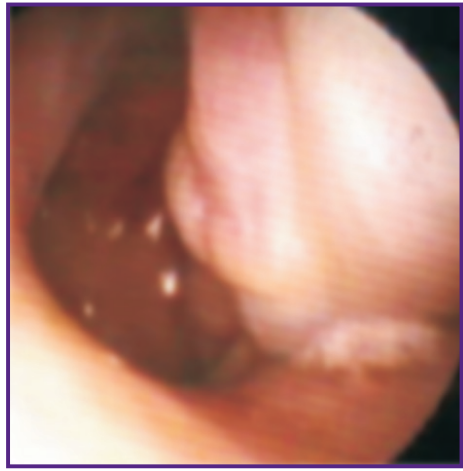

Figure 1. Fragment of nasal video-endoscopy of patient S., 8 years old, diagnosed with bronchial asthma (atopic, persistent, under control), allergic rhinitis (persistent, severe) in the stage of exacerbation, and hypertrophy of the mucous membrane in the posterior parts of the inferior conchae

Hypertrophic changes in the mucous membrane of the posterior ends of the inferior conchae. Periostin level in the nasal secretion is $10.7 \mathrm{ng} / \mathrm{mg}$

values of periostin in patients with normal nasal architectonics $(n=12)$ were $0.15[0.001 ; 0.63] \mathrm{ng} / \mathrm{mg}$, and in children with anomalies of intranasal structures $(n=21)-0.45[0.001 ; 21.59] \mathrm{ng} / \mathrm{mg}(\mathrm{W}=242.5 ; \mathrm{p}=0.13)$. In children with a normally sized pharyngeal tonsil $(n=13)$, the average periostin value was 0.27 [0.16; 0.81] $\mathrm{ng} / \mathrm{mg}$, whereas in patients with a hypertrophic tonsil $(n=20)$ that was $0.28[0.001 ; 13.28] \mathrm{ng} / \mathrm{mg}(\mathrm{W}=173.0$; $\mathrm{p}=0.74)$.

\section{Discussion}

The study was the first to compare the levels of periostin in the nasal secretion of children with atopic bronchial asthma and various clinical forms of allergic rhinitis. We also aimed to assess the potential significance of nasal periostin as a biomarker of allergic inflammation of the URT and hypertrophic changes in the sinonasal mucosa.

We found that the clinical period of AR determined, to a large degree, the presence of periostin in the nasal secretion of patients. Thus, in the periods of $A R$ exacerbation, the levels of periostin were significantly higher than those during the periods of remission. This is consistent with reports by others indicating that the developing allergic inflammation in the airways is accompanied by an increase in the synthesis of periostin. Lopez-Guisa et al. [44] demonstrated that the expression of periostin genes by nasal epithelial cells after stimulation with IL-4/IL-13 was significantly (3.9-fold) higher in BA patients as compared with nonasthmatics. In a study by Pham et al. [36], abnormally high levels of nasal periostin were found in patients with

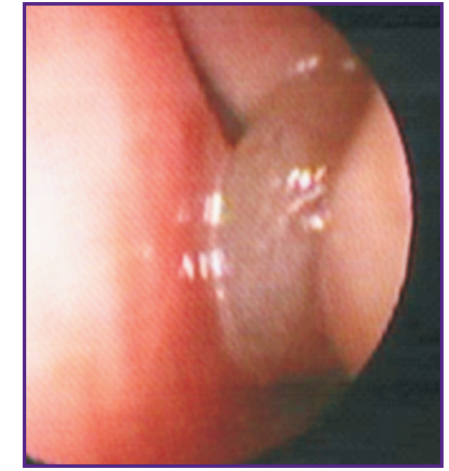

Figure 2. Fragment of nasal video-endoscopy of patient M., 9 years old, diagnosed with bronchial asthma (atopic, mild, intermittent) in remission, allergic rhinosinusitis (persistent), and polypoid rhinosinusitis

Polyposis associated hypertrophy of the mucous membrane that obturates the middle nasal passage on the left. Periostin level in the nasal secretion is $0.056 \mathrm{ng} / \mathrm{mg}$

asthma, and a further increase in periostin was noted during asthma exacerbation.

Likewise, in the present study, an aggravation of $A R$ in patients with asthma was accompanied by a significant accumulation of periostin in nasal secretions; $p=0.048$. Quantification of AR symptoms using the TNSS scale revealed a significant positive correlation between the TNSS scores and the concentrations of periostin in nasal secretions $(R=0.31 ; p=0.04)$. Among the symptoms, rhinorrhea best correlated with periostin levels $(R=0.36 ; p=0.02)$. This result is consistent with the available literature in that an increased expression of periostin correlates with an increased activity of the glands of the respiratory tract and an increased volume of their secretion $[33,45]$.

Thus, if we consider the clinical manifestations of AR as a reflection of allergic inflammation, it can be argued that an intensification of the inflammatory process is accompanied by an increased accumulation of periostin in the nasal secretion. Therefore, the level of nasal periostin can be proposed as a non-invasive biomarker of allergic inflammation of the nasal mucosa in patients with atopic BA combined with AR. This idea is supported by the available data on the involvement of periostin in the genesis of allergic Th2-dependent inflammation in the respiratory tract $[31,33,46,47]$.

Regarding the relation between periostin and hypertrophy of the sinonasal mucosa, our results were less definitive. On the one hand, the level of nasal periostin showed some increase in patients with hypertrophic changes in the NM. On the other hand, this level significantly varied with the clinical variant of sinonasal hypertrophy. In patients with polyposis of the 
sinonasal mucosa, it was 0.17 [0.00; 0.32$] \mathrm{ng} / \mathrm{mg}$, i.e., close to the level of nasal periostin in patients without hypertrophy $(0.18 \quad[0.00 ; 4.30] \quad n g / m g ; \quad p=0.83)$. Furthermore, in children with NM hypertrophy in the medial surface of the conchae, there was significantly more periostin, i.e., $21.6[10.7 ; 1516.8] \mathrm{ng} / \mathrm{mg} ; \mathrm{p}=0.02$. This, however, contradicts the literature data about an increased expression of the gene encoding for periostin and an increase in periostin-protein in sinonasal polyps and systemic bio-substrates [30, 45, 46]. For example, in a study by Asano et al. [48], serum periostin levels in patients with asthma with chronic rhinosinusitis and nasal polyps were significantly higher $(130.0 \pm 46.6 \mathrm{ng} / \mathrm{ml})$ than in patients without nasal polyps $(87.9 \pm 37.7 \mathrm{ng} / \mathrm{ml})$; $p=0.001$. However, they determined periostin in the blood serum, which is a systemic bio-substrate. Lehmann et al. [49] also provide numerous data on increased levels of periostin-protein and the expression of the respective gene in nasal polyps in patients with Th2-dependent inflammation and/or atopic BA.

In our view, this contradiction can be explained by that that the periostin-specific remodeling effects manifest to a higher degree when periostin secretion is directed towards the basement membrane. Additionally, in some cases of pathological remodeling, an increased presence of periostin is more typical of body tissues and systemic bio-substrates, while the accumulation of periostin in local secretions is less pronounced [34].

The major results of this study indicate that an increased level of periostin in the nasal secretion in patients with $B A$ and $A R$ is characteristic of an exacerbation of $A R$ and an increase in the severity of its course. This allows us to consider the concentration of periostin in the nasal secretion as a biomarker of local allergic inflammation of the URT in these patients.

At the same time, the informativity of this biomarker may be ambiguous as far as the hypertrophic changes in the sinonasal mucosa are concerned. The levels of periostin in the nasal secretion of children without sinonasal hypertrophy and children with sinonasal polyposis were close, but significantly lower than those in children with hyperplasia of the mucous membrane of the medial surfaces of the conchae. This fact does not allow us to consider the nasal level of periostin a universal biomarker of sinonasal hypertrophy and requires additional research. It is quite possible that the use of minimally invasive techniques, including a brush biopsy, will make it possible to better assess the informativity of determining periostin as a biomarker of hypertrophic changes in the sinonasal mucosa.

Limitations of this study included the insufficient sample sizes (the numbers of patients) in the compared groups that did not provide for full-fledged statistical analysis. Yet, this work is the first to quantify the level of periostin in the nasal secretion of children with atopic $B A$ and $A R$ and to relate those to the clinical characteristics of the patients. The obtained results lay the ground for further studies using the required sample size and precisely quantify the levels of periostin in the nasal secretion in these patients. At the next stage of the research, it is planned to study the relationship between the level of periostin in the nasal secretion and other biomarkers of inflammation and tissue remodeling in patients with $B A$ and $A R$.

\section{Conclusion}

Exacerbation and increased severity of $A R$ in patients with atopic BA are accompanied by an increase in the concentration of periostin in the nasal secretion. This allows us to consider the level of nasal periostin as a non-invasive biomarker of local allergic inflammation of the nasal mucosa in patients with atopic BA and AR. The accumulation of periostin in a hypertrophic sinonasal mucosa may reflect the clinical form of the hypertrophy and requires additional study.

Research funding. The study was carried out as part of the initiative research into "Study of the clinical and pathogenetic aspects of acquired and congenital diseases of the respiratory system in children" (No.031216-0-000) at the Medical Institute of the Peoples' Friendship University of Russia.

Conflict of interest. The authors have confirmed that there are no obvious and potential conflicts of interest that need to be reported.

\section{References}

1. GINA. Global strategy for asthma management and prevention. 2019. URL: https://ginasthma.org/wp-content/uploads/2019/06/GINA-2019-main-report-June-2019-wms.pdf.

2. Reddel H.K., FitzGerald J.M., Bateman E.D., Bacharier L.B., Becker A., Brusselle G., Buhl R., Cruz A.A., Fleming L., Inoue H., Ko F.W., Krishnan J.A., Levy M.L., Lin J., Pedersen S.E., Sheikh A., Yorgancioglu A., Boulet L.P. GINA 2019: a fundamental change in asthma management: treatment of asthma with short-acting bronchodilators alone is no longer recommended for adults and adolescents. Eur Respir J 2019; 53(6): 1901046, https:// doi.org/10.1183/13993003.01046-2019.

3. Krasilnikova S.V., Eliseeva T.I., Popov K.S., Tush E.V., Khaletskaya O.V., Ovsyannikov D.Y., Balabolkin I.I., Shakhov A.V., Prahov A.V. Multimorbidity of upper respiratory tract pathology in children with bronchial asthma. Pediatria. Zhurnal im. G.N. Speranskogo 2018; 97(2): 19-26.

4. Krasilnikova S.V., Eliseeva T.I., Shakhov A.V., Geppe N.A. Capabilities of nasal videoendoscopy in diagnostics of pharyngeal tonsil condition in children with bronchial asthma. Sovremennye tehnologii $v$ medicine 2016; 8(3): 126-136, https://doi.org/10.17691/stm2016.8.3.15.

5. Krasilnikova S.V., Tush E.V., Babaev S.Yu., Khaletskaya A.I., Popov K.S., Novozhilov A.A., Abubakirov T.E., Eliseeva T.I., Ignatov S.K., Shakhov A.V., Kubysheva N.I., Solovyev V.D. Endonasal infrared thermometry for the diagnosis of allergic inflammation of the nasal mucosa in patients with bronchial asthma. Sovremennye tehnologii $v$ medicine 2017; 9(4): 201-208, https://doi.org/10.17691/ stm2017.9.4.25. 
6. Krasil'nikova S.V., Eliseyeva T.I., Remizova N.V., Soodaeva S.K., Shakhov A.V., Prakhov A.V. Nose and paranasal sinuses pathology in children with bronchial asthma. Pulmonologia 2012; 4: 45-49, https://doi.org/10.18093/08690189-2012-0-4-45-49.

7. Eliseeva T.I., Tush E.V., Krasilnikova S.V., Kuznetsova S.V., Larin R.A., Kubysheva N.I., Khaletskaya O.V., Potemina T.E., Ryazantsev S.V., Ignatov S.K. Metabolism of the extracellular matrix in bronchial asthma (review). Sovremennye tehnologii v medicine 2018; 10(4): 220-234, https://doi.org/10.17691/stm2018.10.4.25.

8. Takabayashi T., Schleimer R.P. Formation of nasal polyps: the roles of innate type 2 inflammation and deposition of fibrin. J Allergy Clin Immunol 2020; 145(3): 740-750, https:// doi.org/10.1016/j.jaci.2020.01.027.

9. Eliseeva T.I., Krasilnikova S.V., Babaev S.Y., Novozhilov A.A., Ovsyannikov D.Y., Ignatov S.K., Kubysheva N.I., Shakhov A.V. Dependence of anterior active rhinomanometry indices on nasal obstructive disorders in children with atopic bronchial asthma complicated by nasal symptoms. Biomed Res Int 2018; 2018: 1869613, https://doi. org/10.1155/2018/1869613.

10. Eliseeva T.I., Krasilnikova S.V., Geppe N.A., Babaev S.Y., Tush E.V., Khaletskaya O.V., Ovsyannikov D.Y., Balabolkin I.I., Ignatov S.K., Kubysheva N.I. Effect of nasal obstructive disorders on sinonasal symptoms in children with different levels of bronchial asthma control. Can Respir J 2018; 2018: 4835823, https://doi.org/10.1155/2018/4835823.

11. Kryukov A.I., Bondareva G.P., Nguen T.F. Allergic rhinitis complicated by hypertrophy of the nasal mucosa: results of a pilot observational study. Russkij medicinskij zurnal 2020; 5: 17-20.

12. Fokkens W.J., Lund V.J., Hopkins C., Hellings P.W., Kern R., Reitsma S., Toppila-Salmi S., Bernal-Sprekelsen M., Mullol J., Alobid I., Terezinha Anselmo-Lima W., Bachert C., Baroody F., von Buchwald C., Cervin A., Cohen N., Constantinidis J., De Gabory L., Desrosiers M., Diamant Z., Douglas R.G., Gevaert P.H., Hafner A., Harvey R.J., Joos G.F., Kalogjera L., Knill A., Kocks J.H., Landis B.N., Limpens J., Lebeer S., Lourenco O., Meco C., Matricardi P.M., O'Mahony L., Philpott C.M., Ryan D., Schlosser R., Senior B., Smith T.L., Teeling T., Tomazic P.V., Wang D.Y., Wang D., Zhang L., Agius A.M., Ahlstrom-Emanuelsson C., Alabri R., Albu S., Alhabash S., Aleksic A., Aloulah M., Al-Qudah M., Alsaleh S., Baban M.A., Baudoin T., Balvers T., Battaglia P., Bedoya J.D., Beule A., Bofares K.M., Braverman I., Brozek-Madry E., Richard B., Callejas C., Carrie S., Caulley L., Chussi D., de Corso E., Coste A., El Hadi U., Elfarouk A., Eloy P.H., Farrokhi S., Felisati G., Ferrari M.D., Fishchuk R., Grayson W., Goncalves P.M., Grdinic B., Grgic V., Hamizan A.W., Heinichen J.V., Husain S., Ping T.I., Ivaska J., Jakimovska F., Jovancevic L., Kakande E., Kamel R., Karpischenko S., Kariyawasam H.H., Kawauchi H., Kjeldsen A., Klimek L., Krzeski A., Kopacheva Barsova G., Kim S.W., Lal D., Letort J.J., Lopatin A., Mahdjoubi A., Mesbahi A., Netkovski J., Nyenbue Tshipukane D., Obando-Valverde A., Okano M., Onerci M., Ong Y.K., Orlandi R., Otori N., Ouennoughy K., Ozkan M., Peric A., Plzak J., Prokopakis E., Prepageran N., Psaltis A., Pugin B., Raftopulos M., Rombaux P., Riechelmann H., Sahtout S., Sarafoleanu C.C., Searyoh K., Rhee C.S., Shi J., Shkoukani M., Shukuryan A.K., Sicak M., Smyth D., Sindvongs K., Soklic Kosak T., Stjarne P., Sutikno B.,
Steinsvag S., Tantilipikorn P., Thanaviratananich S., Tran T., Urbancic J., Valiulius A., Vasquez de Aparicio C., Vicheva D., Virkkula P.M., Vicente G., Voegels R., Wagenmann M.M., Wardani R.S., Welge-Lussen A., Witterick I., Wright E., Zabolotniy D., Zsolt B., Zwetsloot C.P. European position paper on rhinosinusitis and nasal polyps 2020. Rhinology 2020; 58(Suppl S29): 1-464, https://doi.org/10.4193/Rhin20.600.

13. Caimmi D., Matti E., Pelizzo G., Marseglia A., Caimmi S., Labo E., Licari A., Pagella F., Castellazzi A.M., Pusateri A., Parigi G.B., Marseglia G.L. Nasal polyposis in children. J Biol Regul Homeost Agents 2012; 26(1 Suppl): S77-S83.

14. Karpova E.P., Emel'yanova M.P., Tulupov D.A. Polypous rhinosinusitis in the children. Vestnik otorinolaringologii 2016; 81(2): 70-73, https://doi.org/10. 17116/otorino201681270-73.

15. Fokkens W.J., Lund V., Bachert C., Mullol J., Bjermer L., Bousquet J., Canonica G.W., Deneyer L., Desrosiers M., Diamant Z., Han J., Heffler E., Hopkins C., Jankowski R., Joos G., Knill A., Lee J., Lee S.E., Marien G., Pugin B., Senior B., Seys S.F., Hellings P.W. EUFOREA consensus on biologics for CRSwNP with or without asthma. Allergy 2019; 74(12): 2312-2319, https://doi.org/10.1111/all.13875.

16. Banoub R.G., Phillips K.M., Hoehle L.P., Caradonna D.S., Gray S.T., Sedaghat A.R. Relationship between chronic rhinosinusitis exacerbation frequency and asthma control. Laryngoscope 2018; 128(5): 1033-1038, https://doi.org/10.1002/lary.26901.

17. Schlosser R.J., Smith T.L., Mace J., Soler Z.M. Asthma quality of life and control after sinus surgery in patients with chronic rhinosinusitis. Allergy 2017; 72(3): 483-491, https://doi. org/10.1111/all.13048.

18. Orlandi R.R., Kingdom T.T., Hwang P.H., Smith T.L., Alt J.A., Baroody F.M., Batra P.S., Bernal-Sprekelsen M., Bhattacharyya N., Chandra R.K., Chiu A., Citardi M.J., Cohen N.A., DelGaudio J., Desrosiers M., Dhong H.J., Douglas R., Ferguson B., Fokkens W.J., Georgalas C., Goldberg A., Gosepath J., Hamilos D.L., Han J.K., Harvey R., Hellings P., Hopkins C., Jankowski R., Javer A.R., Kern R., Kountakis S., Kowalski M.L., Lane A., Lanza D.C., Lebowitz R., Lee H.M., Lin S.Y., Lund V., Luong A., Mann W., Marple B.F., McMains K.C., Metson R., Naclerio R., Nayak J.V., Otori N., Palmer J.N., Parikh S.R., Passali D., Peters A., Piccirillo J., Poetker D.M., Psaltis A.J., Ramadan H.H., Ramakrishnan V.R., Riechelmann H., Roh H.J., Rudmik L., Sacks R., Schlosser R.J., Senior B.A., Sindwani R., Stankiewicz J.A., Stewart M., Tan B.K., Toskala E., Voegels R., Wang de Y., Weitzel E.K., Wise S., Woodworth B.A., Wormald P.J., Wright E.D., Zhou B., Kennedy D.W. International Consensus Statement on Allergy and Rhinology: Rhinosinusitis. Int Forum Allergy Rhinol 2016; 6(Suppl 1): S22-S209, https://doi. org/10.1002/alr.21695.

19. Kato A. Group 2 innate lymphoid cells in airway diseases. Chest 2019; 156(1): 141-149, https://doi.org/10.1016/j. chest.2019.04.101.

20. Xiang R., Zhang Q.P., Zhang W., Kong Y.G., Tan L., Chen S.M., Deng Y.Q., Tao Z.Z., Xu Y. Different effects of allergic rhinitis on nasal mucosa remodeling in chronic rhinosinusitis with and without nasal polyps. Eur Arch Otorhinolaryngol 2019; 276(1): 115-130, https://doi. org/10.1007/s00405-018-5195-X.

21. Wang X., Zhang N., Bo M., Holtappels G., Zheng M., Lou H., Wang $H_{\text {., }}$ Zhang L., Bachert C. Diversity of $T_{H}$ 
cytokine profiles in patients with chronic rhinosinusitis: a multicenter study in Europe, Asia, and Oceania. J Allergy Clin Immunol 2016; 138(5): 1344-1353, https://doi.org/10.1016/j. jaci.2016.05.041.

22. Emelyanova M.P., Karpova E.P., Tulupov D.A. Polypoid rhinosinusitis in children. Epidemiology and possible causes. Allergologia i immunologia v pediatrii 2017; 1(48): 28-31.

23. Tush E.V., Eliseeva T.I., Khaletskaya O.V., Krasilnikova S.V., Ovsyannikov D.Yu., Potemina T.E., Ignatov S.K. Extracellular matrix markers and methods for their study (review). Sovremennye tehnologii $v$ medicine 2019; 11(2): 133-149, https://doi.org/10.17691/ stm2019.11.2.20.

24. Nakayama T., Sugimoto N., Okada N., Tsurumoto T., Mitsuyoshi R., Takaishi S., Asaka D., Kojima H., Yoshikawa M., Tanaka Y., Haruna S.I. JESREC score and mucosal eosinophilia can predict endotypes of chronic rhinosinusitis with nasal polyps. Auris Nasus Larynx 2019; 46(3): 374-383, https://doi.org/10.1016/j.anl.2018.09.004.

25. Kim D.K., Kang S.I., Kong I.G., Cho Y.H., Song S.K., Hyun S.J., Cho S.D., Han S.Y., Cho S.H., Kim D.W. Twotrack medical treatment strategy according to the clinical scoring system for chronic rhinosinusitis. Allergy Asthma Immunol Res 2018; 10(5): 490-502, https://doi.org/10.4168/ aair.2018.10.5.490.

26. Nomura K., Kojima T., Fuchimoto J., Obata K., Keira T., Himi T., Sawada N. Regulation of interleukin-33 and thymic stromal lymphopoietin in human nasal fibroblasts by proinflammatory cytokines. Laryngoscope 2012; 122(6): 11851192, https://doi.org/10.1002/lary.23261.

27. Ebbo M., Crinier A., Vély F., Vivier E. Innate lymphoid cells: major players in inflammatory diseases. Nat Rev Immunol 2017; 17(11): 665-678, https://doi.org/10.1038/ nri.2017.86.

28. Kouzaki H., O'Grady S.M., Lawrence C.B., Kita H. Proteases induce production of thymic stromal lymphopoietin by airway epithelial cells through protease-activated receptor-2. J Immunol 2009; 183(2): 1427-1434, https://doi.org/10.4049/ jimmunol.0900904.

29. Krasil'nikova S.V., Ovsyannikov D.Yu., Eliseeva T.I., Tush E.V., Bol'shova E.V., Larin R.A., Frolov P.A., Balabolkin I.I. Thymic stromal lymphopoietin as a predictor of hypertrophic changes in the nasal mucosa in children with atopic bronchial asthma and allergic rhinitis. Pediatria. Zhurnal im. G.N. Speranskogo 2020; 99(4): 71-78.

30. Savlevich E.L., Kurbacheva O.M., Egorov V.I., Dyneva M.E., Shilovskiy I.P., Khaitov M.R. Gene expression levels of cytokines in different phenotypes of CRSwNP. Vestnik otorinolaringologii 2019; 84(6): 42-47, https://doi.org/10.17116/ otorino20198406142.

31. Oishi K., Matsunaga K., Shirai T., Hirai K., Gon Y. Role of type2 inflammatory biomarkers in chronic obstructive pulmonary disease. J Clin Med 2020; 9(8): E2670, https://doi. org/10.3390/jcm9082670.

32. Li W., Gao P., Zhi Y., Xu W., Wu Y., Yin J., Zhang J. Periostin: its role in asthma and its potential as a diagnostic or therapeutic target. Respir Res 2015; 16(1): 57, https://doi. org/10.1186/s12931-015-0218-2.

33. Izuhara K., Conway S.J., Moore B.B., Matsumoto H., Holweg C.T., Matthews J.G., Arron J.R. Roles of periostin in respiratory disorders. Am J Respir Crit Care Med 2016; 193(9): 949-956, https://doi.org/10.1164/rccm.2015102032PP.
34. Sidhu S.S., Yuan S., Innes A.L., Kerr S., Woodruff P.G., Hou L., Muller S.J., Fahy J.V. Roles of epithelial cell-derived periostin in TGF-beta activation, collagen production, and collagen gel elasticity in asthma. Proc Natl Acad Sci U S A 2010; 107(32): 14170-14175, https://doi.org/10.1073/ pnas. 1009426107.

35. Hackett T.L. Epithelial-mesenchymal transition in the pathophysiology of airway remodelling in asthma. Curr Opin Allergy Clin Immunol 2012; 12(1): 53-59, https://doi. org/10.1097/ACl.0b013e32834ec6eb.

36. Pham S., Hardin O., Dinwiddie D.L., Bhattacharyya S., Stoner A., Kincaid J.C., Kirkpatrick C., Putt C., Kennedy J.L. Nasal periostin levels and acute symptoms in asthmatics during viral-induced exacerbations. $J$ Allergy Clin Immunol 2019; 143(2): AB206, https://doi.org/10.1016/j. jaci.2018.12.629.

37. Ovsyannikov D.Y., Kuzmenko L.G., Nazarova T.I., Haled M., Frolov P.A., Nguen B.V., Illarionova T.Y., Semyatov S.M., Eliseeva T.I. Clinical and laboratory markers of bacterial infection in children of different ages. Pediatria. Zhurnal im. G.N. Speranskogo 2019; 98(1): 186-192, https://doi. org/10.24110/0031-403X-2019-98-1-186-192.

38. Eliseeva T.I., Balabolkin I.I. Modern technologies of bronchial asthma control in children (review). Sovremennye tehnologii $v$ medicine 2015; 7(2): 168-184, https://doi. org/10.17691/stm2015.7.2.21.

39. Nilova M.Y., Tush E.V., Eliseeva T.I., Krasilnikova S.V., Khaletskaya O.V., Popov K.S., Novikova N.A. Structure of sensitization to aeroallergenes in children with atopic bronchial asthma. Allergologia i immunologia v pediatrii 2019; 2: $17-23$

40. Krouse J., Lund V., Fokkens W., Meltzer E.O. Diagnostic strategies in nasal congestion. Int J Gen Med 2010; 3: 59-67, https://doi.org/10.2147/ijgm.s8084.

41. Juniper E.F., Gruffydd-Jones K., Ward S., Svensson K. Asthma Control Questionnaire in children: validation, measurement properties, interpretation. Eur Respir J 2010; 36(6): 1410-1416, https://doi. org/10.1183/09031936.00117509.

42. Watelet J.B., Gevaert P., Holtappels G., Van Cauwenberge P., Bachert C. Collection of nasal secretions for immunological analysis. Eur Arch Otorhinolaryngol 2004; 261(5): 242-246, https://doi.org/10. 1007/s00405-003-0691-y.

43. Rimmer J., Hellings P., Lund V.J., Alobid I., Beale T., Dassi C., Douglas R., Hopkins C., Klimek L., Landis B., Mosges R., Ottaviano G., Psaltis A., Surda P., Tomazic P.V., Vent J., Fokkens W. European position paper on diagnostic tools in rhinology. Rhinology 2019; 57(Suppl S28): 1-41, https://doi.org/10.4193/Rhin19.410.

44. Lopez-Guisa J.M., Powers C., File D., Cochrane E., Jimenez N., Debley J.S. Airway epithelial cells from asthmatic children differentially express proremodeling factors. J Allergy Clin Immunol 2012; 129(4): 990-997.e6, https://doi. org/10.1016/j.jaci.2011.11.035.

45. Wei Y., Ma R., Zhang J., Wu X., Yu G., Hu X., Li J., Liu Z., Ji W., Li H., Wen W. Excessive periostin expression and Th2 response in patients with nasal polyps: association with asthma. J Thorac Dis 2018; 10(12): 6585-6597, https://doi. org/10.21037/jtd.2018.11.12.

46. Qin Z., Li X., Cai X., Li J., Zhu H., Ma Y., Wu S., Liu D. Periostin: a novel biomarker for chronic rhinosinusitis. B-Ent 2016; 12(4): 305-313. 
47. Bobolea I., Barranco P., Del Pozo V., Romero D., Sanz V., Lopez-Carrasco V., Canabal J., Villasante C., Quirce S. Sputum periostin in patients with different severe asthma phenotypes. Allergy 2015; 70(5): 540-546, https://doi. org/10.1111/all.12580.

48. Asano T., Kanemitsu Y., Takemura M., Yokota M., Fukumitsu K., Takeda N., Ichikawa H., Uemura T., Takakuwa O., Ohkubo H., Maeno K., Ito Y., Oguri T., Maki Y., Ono J., Ohta S., Nakamura Y., Izuhara K., Suzuki M.,
Niimi A. Serum periostin as a biomarker for comorbid chronic rhinosinusitis in patients with asthma. Ann Am Thorac Soc 2017; 14(5): 667-675, https://doi.org/10.1513/ annalsats.201609-720oc.

49. Lehmann A.E., Scangas G.A., Bergmark R.W., El Rassi E., Stankovic K.M., Metson R. Periostin and inflammatory disease: implications for chronic rhinosinusitis. Otolaryngol Head Neck Surg 2019; 160(6): 965-973, https:// doi.org/10.1177/0194599819838782. 